\title{
Influence of Chitosan-Alginate Microcapsules Containing Anti-Vibrio Harveyi IgY in the Gastrointestinal Tract Simulation
}

\author{
Kawin Punyokun ${ }^{1,2}$, Ratchanee Hongprayoon ${ }^{1,3}$, Prapansak Srisapoome ${ }^{4} \&$ Theerapol Sirinarumitre ${ }^{5}$ \\ ${ }^{1}$ Center for Agricultural Biotechnology, Kasetsart University, Kamphaeng Saen Campus, Nakhon Pathom, \\ Thailand \\ ${ }^{2}$ Center of Excellence on Agricultural Biotechnology: (AG-BIO/PERDO-CHE), Bangkok, Thailand \\ ${ }^{3}$ Department of Plant Pathology, Faculty of Agriculture at Kamphaeng Saen, Kasetsart University, Nakhon \\ Pathom, Thailand \\ ${ }^{4}$ Department of Aquaculture, Faculty of Fisheries, Kasetsart University, Bangkok, Thailand \\ ${ }^{5}$ Department of Veterinary Pathology, Faculty of Veterinary Medicine, Kasetsart University, Bangkok, Thailand \\ Correspondence: Ratchanee Hongprayoon, Center for Agricultural Biotechnology, Kasetsart University, \\ Kamphaeng Saen Campus, Nakhon Pathom, 73140, Thailand. E-mail: agrrat@ku.ac.th
}

Received: July 1, 2015

doi:10.5539/mas.v9n12p110
Accepted: August 13, $2015 \quad$ Online Published: October 31, 2015

URL: http://dx.doi.org/10.5539/mas.v9n12p110

The research is financed by Center of Excellence on Agricultural Biotechnology: (AG-BIO/PERDO-CHE) and Kasetsart University Research and Development Institute (KURDI).

\begin{abstract}
Egg yolk immunoglobulin ( $\operatorname{IgY})$ is an alternative treatment for the prevention of gastrointestinal infections in pigs, cows, chickens and fish. In our previous report, we preliminarily proved that anti- $V$. harveyi $\operatorname{IgY}$ had effective potential to control luminous disease in black tiger shrimp. However, IgY activity may be reduced or destroyed by gastric conditions, particularly low $\mathrm{pH}$ and digestive enzymes. Therefore, it is necessary to find an effective method to preserve the therapeutic function of IgY antibodies during gastric passage. Chitosan-alginate microcapsules have been developed to protect $\operatorname{IgY}$ from gastric inactivation. The processing factors included different forms of chitosan and alginate, while a $\mathrm{CaCl} 2$ concentration and encapsulation medium was investigated. The optimum results were obtained under the following conditions: High $\mathrm{Mw}$ chitosan concentration $0.2 \%(\mathrm{w} / \mathrm{v})$, medium viscosity alginate concentration $2 \%(\mathrm{w} / \mathrm{v}), \mathrm{CaCl} 2$ concentration $0.5 \%(\mathrm{w} / \mathrm{v})$. The stability of $\operatorname{IgY}$ in simulated gastric fluid (SGF, $\mathrm{pH}$ 1.2) was greatly improved by encapsulation in chitosan-alginate microcapsules, and retained greater than $90 \%$ activity after $2 \mathrm{~h}$ exposure to SGF. Less than $10 \%$ IgY was released upon the microcapsules' exposure to SGF for $2 \mathrm{~h}$, and more than $80 \% \operatorname{IgY}$ was released upon the microcapsules' exposure to simulated intestinal fluid (SIF, pH 6.8) for $16 \mathrm{~h}$.
\end{abstract}

Keywords: chitosan-alginate, microencapsulation, vibrio harveyi, $\operatorname{IgY}$

\section{Introduction}

The underlying principle of passive immunization is to employ antibodies taken from other animals to build long-term resistance to disease. This approach has become increasingly popular and its therapeutic properties may represent a viable alternative to other conventional techniques (Hatta, Ozeki, \& Tsuda, 1997). There is evidence to suggest that immunoglobulin from the egg yolks of chickens may be particularly effective in the inhibition of infectious disease (Li-Chan, 1999). The benefits of such findings are especially attractive given that chickens are both inexpensive and easily produced on a large scale (Carlander, Kollberg, Wejaker, \& Larsson, 2000). Testing has revealed that IgY has a high success rate against several enteric pathogens, including bovine and human rotaviruses, enterotoxigenic Escherichia coli (ETEC), Edwardsiella tarda, bovine coronavirus, Yersinia ruckeri, Salmonella spp., Staphylococcus and Pseudomonas when administered orally. When investigated in vitro, IgY was shown to preclude infection and also to limit growth, while in animals it was observed to inhibit the symptoms of infection (Kovacs-Nolan \& Mine, 2004).

In our previous study, "The production of anti-Vibrio harveyi egg yolk immunoglobulin and evaluation of its 
stability and neutralization efficacy" (Srisapoome, Punyokun, Hongprayoon, \& Areechon, 2006; Punyokun, Hongprayoon, Srisapoome, \& Sirinarumitr, 2013), we found that the activity of IgY was destroyed under gastric conditions which contained pepsin or a low $\mathrm{pH}$ value. Otherwise IgY was found to be quite stable in simulated intestinal fluid. Since the primary target site of $\operatorname{IgY}$ is in the small intestine, it is necessary to find an effective method to protect IgY against peptic digestion and acidity in the stomach.

It is possible to control the release of specific active components in foods through a number of techniques based upon microencapsulation. These include extrusion, coacervation, spray cooling or drying, liposome entrapment, nano-encapsulation, and the use of supercritical fluids or spinning disks (Gouin, 2004). Not all of these approaches, however, are equally effective, while some involve the use of prohibitively expensive ingredients. One successful example is the microencapsulation of IgY involving the application of an anionic methacrylic acid copolymer, Eudragit L100-55. Kovacs-Nolan and Mine (2005) reported this particular method to result in significant improvements to the stability of antibodies in simulated gastrointestinal fluid.

Many encapsulated materials contain the polysaccharides, chitosan and alginate, since their properties include biodegradability and biocompatibility, while neither is toxic (Murano, 1998). Both these polysaccharides are polyelectrolytes; as ions, chitosan carries a positive charge while sodium alginate has a negative charge. When alginate and chitosan form a polyelectrolyte complex the binding cannot be reversed, and has greater strength than that between poly-L-lysine and an alginate gel (Thu et al., 1996). The properties of alginate and chitosan have more recently been applied in the production of microcapsules which can be orally administered for the delivery of various encapsulated substances. Peptides, (Hari et al., 1996), proteins (Anal, Bhopatkar, Tokura, Tamura \& Stevens, 2003) and drugs (Anal \& Stevens, 2005) are among the materials to have been delivered to the intestines using encapsulation to bypass the stomach.

The objective of this study was to evaluate the influence of a number of factors upon the retention of anti- $V$. harveyi $\operatorname{IgY}$ under simulate digestive fluid, such as different encapsulation materials, $\mathrm{pH}$ of the encapsulation medium, and the concentration of chitosan, alginate and $\mathrm{CaCl} 2$ during microcapsule manufacture. The microcapsules were subsequently determined under simulated gastric fluid and simulated intestinal fluid. These optimized microcapsules will be applied for IgY oral delivery to shrimp.

\section{Materials and Methods}

Commercialized sodium alginate of differing viscosity (high $>2000 \mathrm{cP}$, medium 500-1000 cP and low 100-250 cP) was purchased from Sigma-Aldrich (St. Louis, MO, USA). This alginate was isolated from the strips of Laminaria hyperborea. The raw materials of N-acetyl-glucosamine were obtained from Asst. Prof. Dr. Rath Pichyangkura, Head of the Center for Chitin-chitosan Biomaterials, Chulalongkorn University, Bangkok, Thailand. There are 3 types of chitosan of different molecular weights (High Mw, Medium Mw and Low Mw). The samples of chitosan and alginate used in the experiments displayed different properties as shown in Table 1.

\subsection{Preparation of Water-Soluble Chitosan by $\mathrm{N}$-acetylation}

Five grams chitosan was dissolved in $100 \mathrm{~mL}$ of $50 \% \mathrm{NaOH}$ at $37^{\circ} \mathrm{C}$ for 5 days. The N-acetylated chitosan was filtered, washed with water and dried at $60^{\circ} \mathrm{C}$. The samples were carried forward for characterization.

\subsection{Measurement of Degree of Deacetylation}

The methods were modified from Muzzarelli \& Rocchetti (1985). Briefly, chitosan solution was prepared in the concentration of $0.01 \mathrm{~g}$ in $100 \mathrm{~mL}$ of $0.01 \mathrm{M}$ acetic acid and was then measured using a UV-spectrophotometer. The distance between the first derivative of the zero crossing point and that of the sample was measured and the degree of deacetylation calculated.

\subsection{Measurement of Moisture Content and Solubility of Chitosan}

The AOAC method 943.01 was used to measure the moisture content. The sample was dried at $105^{\circ} \mathrm{C}$ for $24 \mathrm{~h}$ or until the weight was constant. The moisture content was then calculated by percentage of weight loss compared to the initial weight of the sample. The solubility of chitosan was modified from Roberts (1992). Chitosan $0.2 \mathrm{~g}$ was dissolved in $100 \mathrm{~mL}$ of $0.2 \mathrm{M}$ acetic acid and shaken at $100 \mathrm{rpm}$, at room temperature for $24 \mathrm{~h}$. This solution was filtered through GF/C filter paper and the amount of oven dried insoluble matter was measured. The solubility was calculated from this amount of insoluble matter based on the initial weight of the chitosan after drying at $105^{\circ} \mathrm{C}$ for $24 \mathrm{~h}$.

\subsection{Measurement of Chitosan Molecular Weight}

Gel permeation chromatography methods were available to evaluate the molecular weight distribution of the chitosan sample where calibration was performed by means of commercial standard methods. The sample was 
analyzed at National Metal and Materials Technology, Bangkok, Thailand. Briefly, chitosan solution in $0.2 \% \mathrm{w} / \mathrm{v}$ in $0.5 \mathrm{M}$ acetate buffer was filtrated by $0.45 \mu \mathrm{m}$ filter. $20 \mu \mathrm{L}$ of solution was injected to the gel permeation chromatography model Waters 600E equipped with an ultrahydrogel linear 1 column and guard column; 1,000-20,000,000 Mw resolving range. Pullulanase (Mw 5,900-788,000) was set as the polymer standard.

\subsection{Preparation of Anti-V. harveyi IgY}

Specific IgY anti-V. harveyi strain AQVH001 was prepared from Roman-Brown laying hens and purified with the water dilution method as described previously (Punyokun et al., 2013). IgY powder was obtained and followed by freeze-drying, and its antibody titer was over 250,000 based on indirect ELISA.

\subsection{Preparation of IgY-Chitosan-Alginate Microcapsules}

Microcapsules were prepared by the complex coacervation procedure described by Vandenberg, Drolet, Scott, and de la Noüe (2001). IgY (purified as described above) was added into $2 \%(\mathrm{w} / \mathrm{v})$ sodium alginate at $25 \%$ loading rate (IgY: alginate). Chitosan $0.2 \%(\mathrm{w} / \mathrm{v})$ was dissolved in $1 \%(\mathrm{v} / \mathrm{v})$ acetic acid with gentle warming for $1 \mathrm{~h}$. The encapsulation medium was prepared by mixing $0.2 \%(\mathrm{w} / \mathrm{v})$ chitosan with $1.5 \%(\mathrm{w} / \mathrm{v}) \mathrm{CaCl} 2$ solution. The encapsulation $\mathrm{pH}$ was adjusted to 4.0 with $4 \mathrm{M} \mathrm{NaOH}$. Approximately $50 \mathrm{~mL}$ of alginate-IgY solution was pumped at a rate $4 \mathrm{~mL} / \mathrm{min}$ through a $1.4 \mathrm{~mm}$ nozzle with a coaxial air compressor. Alginate-IgY was extruded into $500 \mathrm{~mL}$ encapsulation medium under mechanical stirring for $15 \mathrm{~min}$. The microcapsules were filtered from the encapsulation medium, rinsed with $0.1 \mathrm{~N} \mathrm{HCl}$ and dried at $40^{\circ} \mathrm{C}$. The surface morphology of the microcapsules was examined using an inverted microscope. The physical factors were tested, including alginate concentration $(1 \%, 1.5 \%, 2 \%, 3 \%(\mathrm{w} / \mathrm{v}))$, chitosan concentration $(0 \%, 0.1 \%, 0.2 \%, 0.5 \%(\mathrm{w} / \mathrm{v})), \mathrm{CaCl} 2$ concentration $(0.1 \%, 0.5 \%, 1 \%, 1.5 \%(\mathrm{w} / \mathrm{v}))$, and $\mathrm{pH}$ of encapsulation medium $(3.0,4.0,5.0,6.0)$.

\subsection{Determination of IgY Retention}

The method was modified from Li et al. (2007). IgY retention was expressed as the percentage of total available $\operatorname{IgY}$ in the microcapsules. The \% IgY retention of IgY capsules was calculated from the IgY content of dried microcapsules after incubation in simulated intestinal fluid (SIF, $0.05 \mathrm{M} \mathrm{K} 2 \mathrm{HPO} 4, \mathrm{pH} 6.8$ ) for $6 \mathrm{~h}$ and the $\operatorname{IgY}$ content of dried microcapsules in releasing buffer $(0.06 \mathrm{M} \mathrm{Na} 3 \mathrm{C} 6 \mathrm{H} 5 \mathrm{O} 7 \cdot 2 \mathrm{H} 2 \mathrm{O}+0.2 \mathrm{M} \mathrm{NaHCO} 3 \mathrm{pH} 8)$. Briefly, $25 \mathrm{mg} \mathrm{IgY}$ capsules were incubated in $5 \mathrm{~mL} \mathrm{SGF}(0.03 \mathrm{M} \mathrm{NaCl}, \mathrm{pH} 1.2)$ for $2 \mathrm{~h}$ with a rotating agitator. The IgY capsules were subsequently transferred and incubated in SIF (0.05 M K2HPO4, pH 6.8) for $6 \mathrm{~h}$. Experiments were performed in triplicate. The samples were determined for protein using a Coomassie Plus Assay Reagent (Thermoscientific, USA). The \% IgY retention was obtained by the Equation:

$$
\text { IgY Retention (\%) } \frac{\operatorname{Ig} Y \text { content after SIF incubation }}{\operatorname{Ig} Y \text { content after release buffer incubation }} \times 100=
$$

\subsection{In Vitro IgY Release from the Microcapsules}

IgY release was described by Anal et al. (2003). $20 \mathrm{mg}$ of IgY capsules was dissolved in $5 \mathrm{~mL}$ of simulated gastric fluid (SGF, $0.03 \mathrm{M} \mathrm{NaCl}, \mathrm{pH} 1.2$ ) without pepsin, at $37^{\circ} \mathrm{C}$, with a rotating agitator for $2 \mathrm{~h}$. The $\operatorname{IgY}$ capsules were subsequently transferred and incubated in $5 \mathrm{~mL}$ of SIF without pancreatin (United States Pharmacopeial Convention Council of Experts, 2004) with a rotating agitator for $16 \mathrm{~h}$. After incubation $20 \mu \mathrm{L}$ aliquots were taken at 1, 2, 3, 4, 6 and $16 \mathrm{~h}$ and replaced with the same volume of fresh medium. Experiments were performed in triplicate. The protein concentration was analyzed using Coomassie Plus Assay Reagent. The accumulative release percentage $(\mathrm{Q} \%)$ was calculated by Equation (1):

$$
\mathrm{Q} \%=\left(C_{n} \times V+V_{i=0}^{n=I} C_{i}\right) /\left(W_{\lg Y} \times \operatorname{Ig} Y \text { loading } \%\right) \times 100 \%
$$

where $C n$ is the sample concentration at $T n, \mathrm{~V}$ is the total volume of release medium, $V i$ is the sampling volume at $T i$, and $C i$ is the sample concentration at $T i$ (both $V O$ and $C O$ were equal to zero).

The $\operatorname{IgY}$ loading percentage is given by Equation (2) where $\operatorname{Cg} Y$ is the concentration of $\operatorname{IgY}$ in the sample, $V$ is the volume of the sample, and $W$ is the weight of the $\operatorname{IgY}$ microcapsules.

$$
\operatorname{IgY} \text { loading } \%=C_{I g Y} \times \frac{V}{W} \times 100 \%
$$

\subsection{Determination of IgY Activity}

The sampling at 1, 2, 3, 4, 6 and $16 \mathrm{~h}$ from the in vitro $\operatorname{IgY}$ release experiment was confirmed in its activity by 
indirect ELISA. A polystyrene plate was coated with $V$. harveyi $10^{8}$ cells $/ \mathrm{mL}$ in $0.05 \mathrm{M}$ bicarbonate buffer, $\mathrm{pH}$ 9.6, $50 \mu \mathrm{L} /$ well and incubated at $37^{\circ} \mathrm{C}$ overnight. The plate was washed three times with PBS containing $0.05 \%$ Tween 20 (PBST), $200 \mu \mathrm{L} /$ well. A blocking buffer (5\% skimmed milk in PBS) was added at $100 \mu \mathrm{L} / \mathrm{well}$ and incubated at $37^{\circ} \mathrm{C}$ for $1 \mathrm{~h}$. The plate was then washed three times with PBST. The IgY sample was diluted 2-fold with blocking buffer then $50 \mu \mathrm{L}$ was added to each well and incubated at $37^{\circ} \mathrm{C}$ for $1 \mathrm{~h}$. The plate was washed again as above and $50 \mu \mathrm{L}$ of alkaline-phosphatase-conjugated rabbit anti-chicken IgG (Sigma Chemical Co., USA) diluted 5000-fold with PBS was added to each well. After incubation at $37^{\circ} \mathrm{C}$ for $1 \mathrm{~h}$, the plate was washed and followed by the addition of $100 \mu \mathrm{L}$ of $p$-nitrophenyl phosphate in diethanolamine buffer (pH 8.9) (Sigma Chemical Co., USA). After incubation at $37^{\circ} \mathrm{C}$ for $30 \mathrm{~min}, 50 \mu \mathrm{L}$ of $3 \mathrm{~N} \mathrm{NaOH}$ was applied to arrest the reaction. The color developed was read at $405 \mathrm{~nm}$ with an ELISA reader (Labsystem, USA).

\subsection{Statistical Analysis}

The results were constructed to determine one-way analysis of variance (ANOVA) which followed a completely randomized design (CRD), while Duncan's new multiple range test (DMRT) was used to compare the differences of observed average values among groups at the significance level of $\alpha=0.05$.

\section{Results and Discussion}

\subsection{Chitosan Characterization}

The properties of chitosan of different molecular weights are shown in Table 1.

Table 1. Properties of high (HMw), medium (MMw) and low (LMw) molecular weight chitosan

\begin{tabular}{ccccc}
\hline Chitosan & $\begin{array}{c}\text { Deacetylation } \\
(\%)\end{array}$ & $\begin{array}{c}\text { Moisture content } \\
(\%)\end{array}$ & $\begin{array}{c}\text { Solubility } \\
(\%)\end{array}$ & $\begin{array}{c}\text { Molecular weight } \\
(\mathrm{kDa})\end{array}$ \\
\hline $\mathrm{HMw}$ & $92.98 \pm 0.16$ & $10.53 \pm 0.03$ & $95.39 \pm 0.97$ & $3.5 \times 10^{6}$ \\
$\mathrm{MMw}$ & $92.47 \pm 0.12$ & $10.67 \pm 0.03$ & $94.42 \pm 0.65$ & $2.1 \times 10^{5}$ \\
$\mathrm{LMw}$ & $86.25 \pm 0.16$ & $15.32 \pm 0.13$ & $92.68 \pm 0.97$ & $1.3 \times 10^{4}$ \\
\hline
\end{tabular}

\subsection{Morphology of IgY Microcapsules}

According to the optimal encapsulation condition, IgY-loaded chitosan-alginate microcapsules were obtained. The mean diameter of microcapsules visualized using an inverted microscope was approximately $1,000-1,500$ $\mu \mathrm{m}$. (Figure 1A). However, the size was decreased to about $100-200 \mu \mathrm{m}$ under feed air volume $0.3 \mathrm{~m}^{3} / \mathrm{h}$ during the extrusion process (Figure 1B).
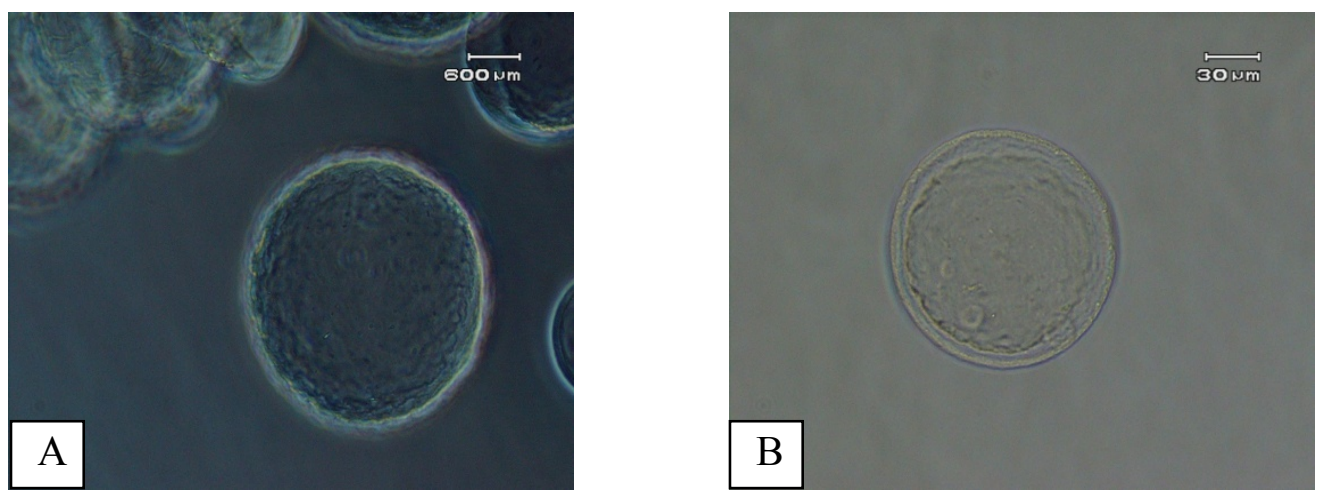

Figure 1. Inverted microscope micrographs of IgY-loaded chitosan-alginate microcapsules. (A) extrusion without air and (B) extrusion with air volume $0.3 \mathrm{~m}^{3} / \mathrm{h}$

\subsection{Studies on Optimal Conditions for IgY Microcapsule Preparation}

The influence of protein retention in IgY microcapsules during different manufacture processes was investigated. IgY retention was increased significantly when the alginate concentration increased and was maximized at $2.5 \%$ $(\mathrm{w} / \mathrm{v})$ alginate (Figure 2A). However, increasing the alginate concentration above $2 \%(\mathrm{w} / \mathrm{v})$ made extrusion extremely difficult, due to the high viscosity of the alginate causing sticking in the nozzle. Bartkowiak and 
Hunkeler (2000) described the results of an increase in alginate concentration upon protein retention. Typically the alginate gradient is amplified when microcapsules are externally gelled, hence causing lower permeability of the microcapsule.

The addition of different concentrations of chitosan $(0.1 \%, 0.2 \%, 0.5 \%(\mathrm{w} / \mathrm{v}))$ into the encapsulation medium showed about $80 \%$ IgY retention but did not differ significantly between treatments. IgY capsules manufactured without chitosan showed only $60 \% \mathrm{IgY}$ retention (Figure $2 \mathrm{~B}$ ). When polycationic polymers are added to the encapsulation medium, the result is to change the physical characteristics of the microcapsule, so both swelling and permeability are reduced (Thu et al., 1996).

The effect of increasing $\mathrm{CaCl} 2$ concentrations in the encapsulation medium on $\mathrm{IgY}$ retention is shown in Figure $2 \mathrm{C}$. IgY retention was higher at lower calcium levels and highest at $0.1 \%(\mathrm{w} / \mathrm{v})$. The concentration of calcium in the encapsulation medium is an important influence on the level of protein retention. Smidsrød and Skjåk-Bræk (1990) showed that the rate of polymer diffusion determines the degree of alginate in homogeneity, while the rate of inward calcium ion diffusion toward the gelling front also exerts a strong influence. Therefore any reduction in the concentration of external calcium will also reduce the calcium diffusion rate towards the gelling front and thus raise the alginate gradient and cut the permeability of the microcapsule.

The $\mathrm{IgY}$ retention of microcapsules during manufacture from various $\mathrm{pH}$ levels of the encapsulation medium was demonstrated in Figure 2D. IgY retention was significantly increased when $\mathrm{pH}$ was increased from 3.0 to 6.0. This experiment found that $\mathrm{pH} 4.0$ gave the highest IgY retention (81\%). It has not yet been precisely determined how $\mathrm{pH}$ interacts during the process of encapsulation. The literature is inconclusive, with Vandenberg et al. (2001) finding that the encapsulation $\mathrm{pH}$ did not influence the efficiency, while Polk et al. (1994) and Huguet, Groboillot, Neufeld, Poncelet, and Dellacherie (1994) claimed that a lower pH resulted in reduced capsule strength and flexibility.
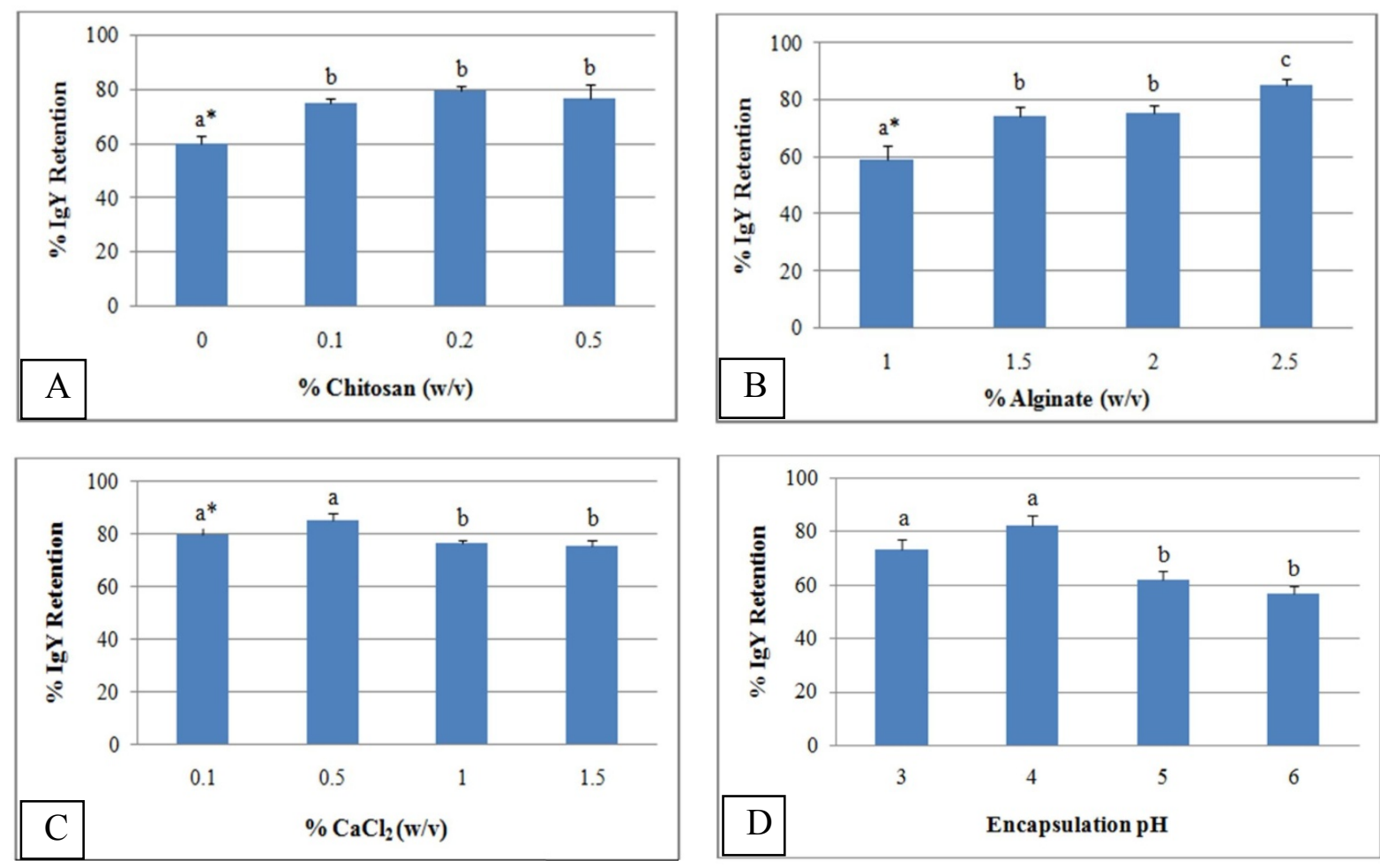

Figure 2. Protein retention during the manufacture of chitosan-alginate microcapsules produced by varying the concentrations of alginate (A), chitosan (B), $\mathrm{CaCl} 2(\mathrm{C})$ and $\mathrm{pH}$ of the encapsulation medium (D). Error bars represent the standard error of the mean based on four replicated microcapsule samples

\subsection{In Vitro IgY Release}

The release characteristics of IgY microcapsules, according to the optimal formulation ( $2 \% \mathrm{w} / \mathrm{v}$ alginate, $0.1 \%$ w/v chitosan, $0.5 \% \mathrm{CaCl} 2$ and adjusted encapsulation to 4.0 ), were examined by incubating in the simulated 
digestive fluid. IgY microcapsules were first incubated in SGF and subsequently in SIF, and the percentage of protein released over time was measured (Figure 3). About $5 \%$ of IgY was released over $2 \mathrm{~h}$ of SGF incubation. After transfer to SIF, the granules began to disintegrate, releasing over $60 \%$ of their protein within $2 \mathrm{~h}$. The granules continued to disintegrate, reaching $80 \%$ release after $16 \mathrm{~h}$ incubation (Figure 4). Anal et al. (2003) gave the following description of chitosan-alginate microcapsule disintegration. When the medium is acidic, ionic bonds in the microcapsules prevent the disintegration of the microcapsule matrix material. However, when the $\mathrm{pH}$ level becomes neutral, hydroxyl ions displace the anionic alginate in the Ca-alginate-chitosan complex, while the chitosan no longer carries a positive charge. This enables the matrix to swell and the complex to disintegrate, thereby releasing the contents of the capsule.

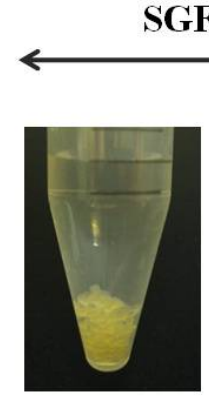

$1 \mathbf{h}$

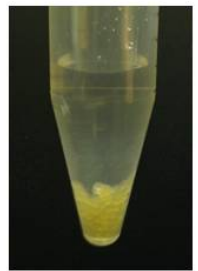

2 h

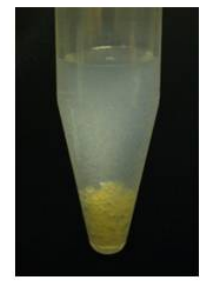

3 h

SIF pH 6.8

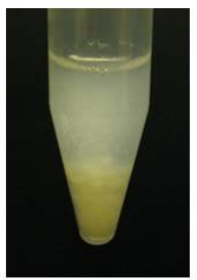

$4 \mathrm{~h}$

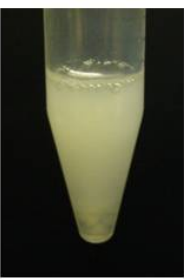

$6 \mathrm{~h}$

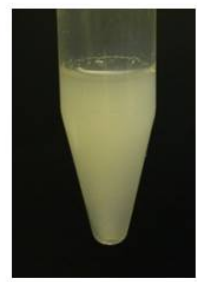

$16 \mathrm{~h}$

Figure 3. Characterization of IgY loaded microcapsules during incubation. Samples were first incubated in simulated gastric fluid for $2 \mathrm{~h}$, and then transferred to simulated intestinal fluid for $16 \mathrm{~h}$

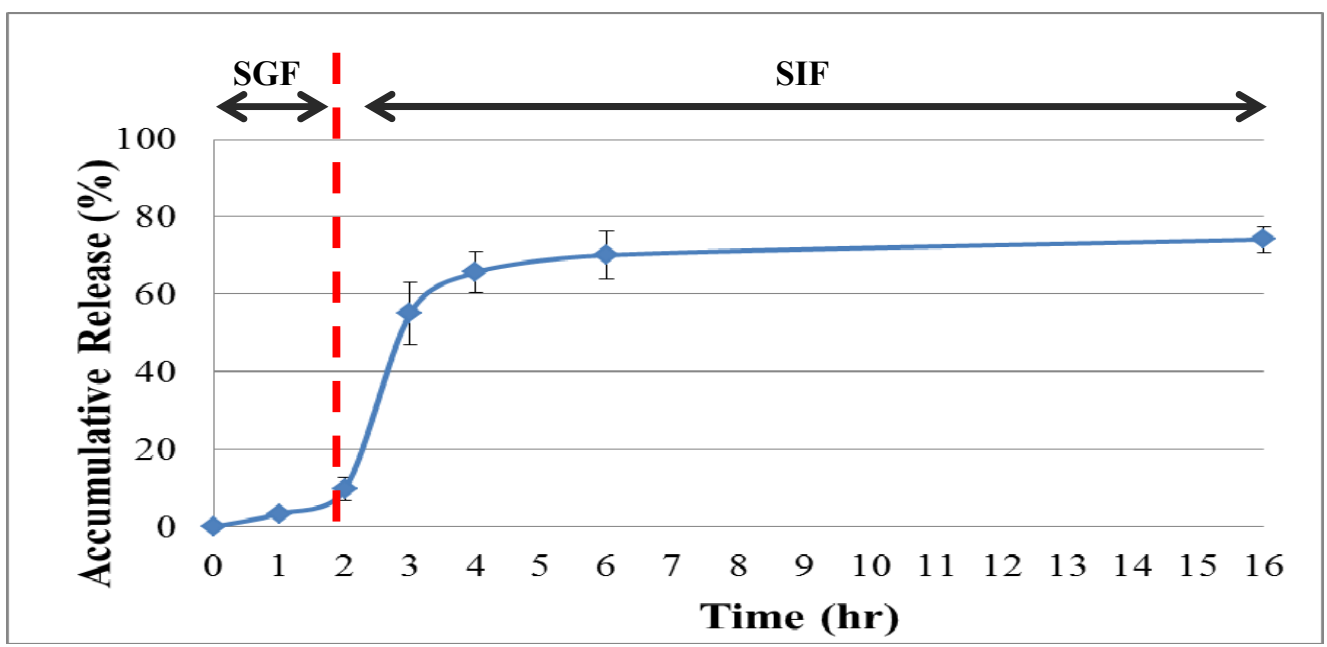

Figure 4. In vitro IgY release from IgY loaded microcapsules. Samples were first incubated in simulated gastric fluid for $2 \mathrm{~h}$, and then transferred to simulated intestinal fluid for $16 \mathrm{~h}$. The percentage of accumulative release was calculated. Data are presented as mean $\pm \mathrm{SD}(\mathrm{n}=3)$

\section{Conclusions}

The creation of optimized chitosan-alginate microcapsules relies upon the application of the various physical and chemical properties of the materials used. In their optimal form, these microcapsules can prevent gastric inactivation in anti- $V$. harveyi $\operatorname{IgY}$, while demonstrating both quick release in the intestines and limited losses due to gastric fluids. The outcome of this study suggests that IgY may have beneficial applications in the food industry, or as an animal feed supplement since it is able to prevent infections caused by digestive pathogenic bacteria in animals.

Further research on IgY is required to maximize the benefits for the food industry. The effect IgY should be investigated on other shrimp diseases to test its application as an antibody. 


\section{Acknowledgements}

This research is supported by the Center for Agricultural Biotechnology, Postgraduate Education and Research Development Office, Commission on Higher Education, Ministry of Education and Kasetsart University Research and Development Institute (KURDI).

\section{References}

Anal, A. K., \& Stevens, W. F. (2005). Chitosan-alginate multilayer beads for controlled release of ampicillin. Int. J. Pharm., 290, 45-54. http://dx.doi.org/10.1016/j.ijpharm.2004.11.015

Anal, A. K., Bhopatkar, D., Tokura, S., Tamura, H., \& Stevens, W. F. (2003). Chitosan-alginate multilayer beads for gastric passage and controlled intestinal release of protein. Drug Dev. Ind. Pharm, 29, 713-724. http://dx.doi.org/10.1081/DDC-120021320

Bartkowiak, A., \& Hunkeler, D. (2000). Alginate-oligochitosan microcapsules. II. Control of mechanical resistance and permeability of the membrane. Chem. Mater., 12(1), $206-212$. http://dx.doi.org/10.1021/cm991128m

Carlander, D., Kollberg, H., Wejaker, P. E., \& Larsson, A. (2000). Peroral immunotherapy with yolk antibodies for the prevention and treatment of enteric infections. Immunol. Res, 21, 1-6. http://dx.doi.org/ 10.1385/IR:21:1:1

Gouin, S. (2004). Microencapsulation: industrial appraisal of existing technologies and trends. Trends Food Sci Tech., 15, 330-347. http://dx.doi.org/10.1016/j.tifs.2003.10.005

Hari, P. R., Chandy, T., \& Sharma, C. P. (1996). Chitosan/calcium-alginate beads for oral delivery of insulin. J. Appl. Polym. Sci., 59, 1795-1801.

Hatta, H., Ozeki, M., \& Tsuda, K. (1997). Egg Yolk Antibody and its Application: Their Basic and Applied Science,. In T. Yamamoto, L. R Juneja, H. Hatta, \& M. Kim (Eds.), Hen Eggs (pp. 151-178). Boca Raton, Florida, U.S.A: CRC Press Inc http://dx.doi.org/ 10.1002/(SICI)1097-4628(19960314)59:11<1795::AID-APP16>3.0.CO;2-T

Huguet, M. L., Groboillot, A., Neufeld, R. J., Poncelet, D., \& Dellacherie, E. (1994). Hemoglobin encapsulation in chitosan/calcium alginate beads. J. Appl. Polym. Sci., 51, 1427-1432. http://dx.doi.org/ 10.1002/app.1994.070510810

Kovacs-Nolan, J., \& Mine, Y. (2004). Avian egg antibodies: basic and potential applications. Avian Poult. Biol. Rev., 15, 25-46. http://dx.doi.org/10.3184/147020604783637462

Kovacs-Nolan, J., \& Mine, Y. (2005). Microencapsulation for the gastric passage and controlled intestinal release of immunoglobulin Y. J. Immunol. Methods., 296, 199-209. http://dx.doi.org/10.1016/j.jim.2004.11.017

Li, X. Y., Jin, L. J. McAllister, T. A., Stanford, K., Xu, J. Y., Lu, Y. N., \& Xu, X. P. (2007). Chitosan-alginate microcapsules for oral delivery of egg yolk immunoglobulin (IgY). J. Agric. Food Chem., 55, $2911-2917$. http://dx.doi.org/ 10.1021/jf062900q

Li-Chan, E. C. Y. (1999). Applications of egg immunoglobulins in immunoaffinity chromatography. In J. S. Sim, S. Nakai \& W. Guenter (Eds.). Egg Nutrition and Biotechnology (pp. 323-339). Wallingford, U.K.: CABI Publishing Press.

Murano, E. (1998). Use of natural polysaccharides in the microencapsulation techniques. J. Appl. Ichthyol., 14, 245-249. http://dx.doi.org/10.1111/j.1439-0426.1998.tb00650.x

Muzzarelli, R. A. A., \& Rocchetti, R. (1985). Determination of the degree of acetylation of chitosan by first derivative ultraviolet spectrophotometry. Carbohyd. Polym., 5, 461-472. http://dx.doi.org/10.1016/0144-8617(85)90005-0

Polk, A. E., Amsden, B., Scarratt, D. J., Gonzal, A., Okhamafe, A. O., \& Goosen, M. F. A. (1994). Oral delivery in aquaculture: controlled release of proteins from chitosan-alginate microcapsules. Aquacult. Eng., 13(4), 311-323. http://dx.doi.org/10.1016/0144-8609(94)90018-3

Punyokun, K., Hongprayoon, R., Srisapoome, P., \& Sirinarumitr, T. (2013). The production of anti-Vibrio harveyi egg yolk immunoglobulin and evaluation of its stability and neutralization efficacy. Food and Agric. Immunol., 24(3), 279-294. http://dx.doi.org/ 10.1080/09540105.2012.684203

Roberts, G. A. F. (1992). Chitin Chemistry. London, UK: The Macmillan Press. 
Smidsrød, O., \& Skjåk-Bræk, G. (1990). Alginate as immobilization matrix for cells. Trends Biotechnol., 8(3), 71-78. http://dx.doi.org/10.1016/0167-7799(90)90139-O

Srisapoome, P., Punyokun, K., Hongprayoon, R., \& Areechon, N. (2006). Passive immunization of anti-Vibrio harveyi egg yolk immunoglobulin against luminous disease in black tiger shrimp (Penaeus monodon). In Proceedings of the $44^{\text {th }}$ Kasetsart University Annual Conference, January 30-February 2, 2006 (pp.365-374). Bangkok, Thailand.

Thu, B., Bruheim, P., Espevik, T., Smidsrød, O., Soon Shiong, P., \& Skjåk-Bræk, G. (1996). Alginate polycation microcapsules. II. Some functional properties. Biomaterials, 17(11), 1069-1079. http://dx.doi.org/10.1016/0142-9612(96)85907-2

United States Pharmacopeial Convention Council of Experts. (2004). Simulated gastric fluid, TS. In Board of Trustees (Eds.), The United States Pharmacopeia 27. The National Formulary, 22, 278. United States Pharmacopeial Convention, Rockville, MD.

Vandenberg, G. W., Drolet, C., Scott, S. L., \& de la Noüe, J. (2001). Factors affecting protein release from alginate-chitosan coacervate microcapsules during production and gastric/intestinal simulation. J. Control. Release, 77, 297-307. http://dx.doi.org/10.1016/S0168-3659(01)00517-X

\section{Copyrights}

Copyright for this article is retained by the author(s), with first publication rights granted to the journal.

This is an open-access article distributed under the terms and conditions of the Creative Commons Attribution license (http://creativecommons.org/licenses/by/3.0/). 